\title{
State infant mortality: an ecologic study to determine modifiable risks and adjusted infant mortality rates.
}

\author{
David A. Paul. MD \\ Thomas Jefferson University \\ Amy Mackley, RNC \\ Christiana Care Health Services \\ Robert G. Locke, DO \\ Thomas Jefferson University \\ John L. Stefano, MD \\ Thomas Jefferson University \\ Charlan Kroelinger, PhD \\ Delaware Health and Socjal Services, Division of Public Health \\ Follow this and additional works at: https://jdc.jefferson.edu/pedsfp \\ Part of the Bioethics and Medical Ethics Commons, and the Pediatrics Commons \\ Let us know how access to this document benefits you
}

\section{Recommended Citation}

Paul. MD, David A.; Mackley, RNC, Amy; Locke, DO, Robert G.; Stefano, MD, John L.; and

Kroelinger, PhD, Charlan, "State infant mortality: an ecologic study to determine modifiable risks and adjusted infant mortality rates." (2009). Department of Pediatrics Faculty Papers. Paper 19. https://jdc.jefferson.edu/pedsfp/19

This Article is brought to you for free and open access by the Jefferson Digital Commons. The Jefferson Digital Commons is a service of Thomas Jefferson University's Center for Teaching and Learning (CTL). The Commons is a showcase for Jefferson books and journals, peer-reviewed scholarly publications, unique historical collections from the University archives, and teaching tools. The Jefferson Digital Commons allows researchers and interested readers anywhere in the world to learn about and keep up to date with Jefferson scholarship. This article has been accepted for inclusion in Department of Pediatrics Faculty Papers by an authorized administrator of the Jefferson Digital Commons. For more information, please contact: JeffersonDigitalCommons@jefferson.edu. 


\author{
As submitted to: \\ Maternal and Child Health Journal \\ and published as: \\ Maternal and Child Health Journal \\ Volume 13, Issue 3, 2009, Pages 343-348 \\ DOI: $10.1007 / \mathrm{s} 10995-008-0358-9$ \\ PubMed ID: 18473130
}

\title{
"State Infant Mortality: An Ecologic Study to Determine Modifiable Risks and Adjusted Infant Mortality Rates"
}

David A. Paul, MD ${ }^{1,2}$, Amy Mackley, RNC ${ }^{1}$, Robert G. Locke, DO ${ }^{1,2}$, John L. Stefano, $\mathrm{MD}^{1,2}$, Charlan Kroelinger, $\mathrm{PhD}^{3}$

1. Pediatrics and Neonatology, Christiana Care Health Services, Newark, DE, USA

2. Pediatrics, Thomas Jefferson University, Philadelphia, PA, USA

3. Center for Excellence in Maternal Child Health and Epidemiology, Delaware Health and Social Services, Division of Public Health, Dover, DE, USA

Corresponding Author:

David A. Paul, MD

MAP-1, Suite 217

Christiana Hospital 
4745 Ogeltown-Stanton, Rd

Newark, DE 19713

(302) 7332410

Fax: (302) 7332602

Email:dpaul@christianacare.org 


\begin{abstract}
OBJECTIVE: To determine factors contributing to state Infant Mortality Rates (IMR) and develop an adjusted IMR in the United States for 2001 and 2002.

DESIGN/METHODS: Ecologic study of factors contributing to state IMR. State IMR for 2001 and 2002 were obtained from the United States linked death and birth certificate data from the National Center for Health Statistics. Factors investigated using multivariable linear regression included state racial demographics, ethnicity, state population, median income, education, teen birth rate, proportion of obesity, smoking during pregnancy, diabetes, hypertension, cesarean delivery, prenatal care, health insurance, self report of mental illness, and number of in-vitro fertilization procedures. Final risk adjusted IMR's were standardized and states were compared with the United States adjusted rates.

RESULTS: Models for IMR in individual states in $2001\left(\mathrm{r}^{2}=.66, \mathrm{p}<.01\right)$ and $2002\left(\mathrm{r}^{2}=.81\right.$, $\mathrm{p}<.01)$ were tested. African-American race, teen birth rate, and smoking during pregnancy remained independently associated with state infant mortality rates for 2001 and $2002.95 \%$ Confidence Intervals (CI) were calculated around the regression lines to model the expected IMR. After adjustment, some states maintained a consistent IMR; for instance, Vermont and New Hampshire remained low, while Delaware and Louisiana remained high. However, other states such as Mississippi, which have traditionally high infant mortality rates, remained within the expected 95\% CI for IMR after adjustment indicating confounding affected the initial unadjusted rates. CONCLUSIONS: Non-modifiable demographic variables, including the percentage of
\end{abstract}


non-Hispanic African American and Hispanic populations of the state are major factors contributing to individual variation in state IMR. Race and ethnicity may confound or modify the IMR in states that shifted inside or outside the 95\% CI following adjustment. Other factors including smoking during pregnancy and teen birth rate, which are potentially modifiable, significantly contributed to differences in state IMR. State risk adjusted IMR indicate that other factors impact infant mortality after adjustment by race/ethnicity and other risk factors.

Abbreviations:

IMR Infant Mortality Rate 
Infant mortality in the United States is characterized by many racial and geographic disparities. Non-Hispanic African American infants have an infant mortality rate twice that of non-Hispanic Caucasian infants, while many southern states have higher infant mortality than those states in the northeast ${ }^{1,2}$. The state-specific factors contributing to differing infant mortality rates remain controversial.

The Healthy People 2010 goal is to reduce infant mortality rates in the United States to $4.5 / 1000$ live births ${ }^{1}$ from the present rate of 6.8/1000 live births. To assist programs designed to reduce infant mortality it is beneficial to understand factors which contribute to a state's high or low infant mortality rate and determine which risk factors may be amenable to modification. States may differ in their inherent risk factors for infant mortality, making state comparison of infant mortality difficult. The objective of our study was to determine factors contributing to state infant mortality rates in 2001 and 2002 in the United States. We also aimed to develop an adjusted comparison of state infant mortality rates based on those factors determined to influence infant mortality. 


\section{Methods}

The study design included an exploratory ecologic investigation of state infant mortality rates in the United States in 2001 and 2002. The aggregate data were composed of state linked birth and death certificates for 2001 and 2002 from the National Center for

Health Statistics and National Census Bureau ${ }^{3,4}$. The dependent variables studied were state infant mortality rates in 2001 and 2002. Infant mortality rate was defined in standard fashion as the number of annual infant deaths prior to 1 year of age normalized per 1000 live births. For the purposes of this study, all 50 states as well as the District of Columbia were included in the analysis.

Risk factors were chosen for investigation based on the broad categories and availability of aggregate data at the state level and included the following: state demographics, insurance factors, maternal disease factors, and pregnancy-related factors. Factors were matched as closely as possible to the 2001 and 2002 time period. State demographics including distribution of state population race and ethnicity, median household income, and high school graduation rate were obtained from the National Census Bureau web sight ${ }^{3}$. All other data were obtained from the National Center for Health Statistics and included insurance estimates, pregnancy-related factors, and maternal disease factors ${ }^{4}$. Insurance factors consisted of the percentage of children without health insurance in 2001, and the health expenditure per capita in 1998. The following pregnancy-related factors were also obtained: percentage of births to unmarried mothers for 2003, adolescent birth rate for 2001, caesarean section rate 20002002, and ratio of assisted reproductive technology procedures/per million population in 2001. The percentage of women reporting smoking during pregnancy from 2000-2002 
was obtained. The rate of smoking during pregnancy was not available for California. For the purposes of this analysis the United States mean for smoking during pregnancy was used for California. Maternal disease factors included the percentage of women age 1844 in the state with body mass index (BMI) $<25$ from 2001-2003, and mental health as measured by the percentage of women 18-44 self-reporting that their mental health was not good for $>13$ of the last 30 days. Also investigated were the percentage of women age 18-44 from each state with diabetes and the percentage with hypertension.

Statistical analysis consisted of forward stepwise linear regression to develop a model of state infant mortality rates. Two separate models were created for 2001 and 2002, respectfully, and significantly associated risk factors remained in each model. Those risk factors significantly associated with the IMR were considered strong potential confounders impacting infant mortality. In order to remove the impact of these significant confounding risk factors on infant mortality, the standardized rate ratio was calculated first for the United States, then for each state for both 2001 and $2002^{5}$. The 95\% Confidence Intervals (CI) calculated around the United States standardized rate ratios for 2001 and 2002 were used as the range to determine whether individual states fell within a 'standard' area or were outliers. States were considered to have a high standarized rate ratio if the ratio was greater than the $95 \%$ CI upper limit around the regression line for both the years 2001 and 2002; states were considered to have a low standardized rate ratio below the 95\% CI lower limit for the years 2001 and 2002. All statistical calculations were done using Statistica v7.0 (Tulsa, OK.) 


\section{Results}

Separate models were created for infant mortality for 2001 and 2002 (Table 1). Factors remaining in the model were similar for both 2001 and 2002. Examining the impact of race/ethnicity on the IMR yielded both an increase in risk and a protective effect depending on classification of the infant. The percentage non-Hispanic AfricanAmerican population of a state was directly related to the state's infant mortality rate and was the single most influential factor on the inter-state variability in infant mortality for both 2001 and 2002. By contrast, the percentage of Hispanic ethnicity was inversely associated with infant mortality rates, though this effect on the models for both years was less influential compared with race. Other pregnancy-related and maternal disease factors yielded similar results. Smoking during pregnancy and adolescent birth rates were associated with increasing infant mortality in 2001 and 2002. The percentage of women with normal BMI was inversely correlated with infant mortality rate in 2001, and the cesarean section rate was inversely correlated with infant mortality in 2002. Factors which did not remain in either model included the following: median household income, high school graduation rate, mental health by self report, $\%$ of women with diabetes, $\%$ of women with hypertension, $\%$ of children with health care insurance, personal health care expenditure per capita, $\%$ of mothers receiving prenatal care in $1^{\text {st }}$ trimester, $\%$ births to unmarried mothers, and assisted reproductive technology procedure rate. 


\section{Adjusted Infant Mortality Rates}

Standardized rate ratios for each state were calculated for both 2001 and 2002

(Table 2). For 2001, the overall standardized rate ratio (observed/expected) for the United States was .99 (95\%CI, 97-1.03) and similarly, the standardized rate ratio for 2002 was .99 (95\% CI, .96-1.04). Table 2 lists the standardized rate ratio for every state in both 2001 and 2002. Twenty-two percent (22\%) of all states fell completely within the 'standard' range for 2001 and 2002; 13 states (25\%) fell below the standard range for both time periods and 11 (22\%) fell above the standard range for both years. For 2001 only, 37\% of all states fell within the standard range, while $33 \%$ fell below the range and the remaining $30 \%$ fell above the range. For 2002, 33\% fell within the standard range, $31 \%$ fell below the range and $36 \%$ fell above the standard range. 


\section{Discussion}

The main finding of our multiple regression analysis is that state racial demographics, specifically higher proportion of non-Hispanic African-American population within a state, are associated with increased state infant mortality rates. By contrast, a higher proportion of Hispanic ethnicity was inversely associated with or protective for state infant mortality in 2001 and 2002. Beyond state racial and ethnic demographics, rate of smoking during pregnancy and adolescent birth rate remained associated with state infant mortality rates in both 2001 and 2002. Our multivariate models of infant mortality also were used to develop adjusted infant mortality rates for each state.

In the United States there are well known racial disparities in infant mortality with non-Hispanic African American infants having an infant mortality rate twice that of nonHispanic Caucasian infants ${ }^{2}$. Our finding that U.S. racial demographics were associated with infant mortality rate is consistent with this known disparity. The factor with the greatest contribution to the model was percentage of the population of non-Hispanic African-American ancestry (explained 56\% of the variability in infant mortality in 2001 and $65 \%$ in 2002). Although Hispanic infants are known to have similar infant mortality rates as non-Hispanic Caucasian infants ${ }^{6}$, a high percentage of the Hispanic population in the U.S. was protective for infant mortality.

The association of racial and ethnic demographics with infant mortality has important public health implications. State racial and ethnic demographics may imbue a spectrum of other risk factors such as poverty level, social status, economic status, or 
social networking not measurable at the aggregate level. It is therefore, not surprising that these factors contributed to the majority of the variability of infant mortality between states in our models. Alternatively, other factors which contribute to the high infant mortality rate in the non-Hispanic African American population may be targeted. The specific reasons for increased infant mortality in non-Hispanic African American population are likely multifactorial and require dissection of the race and ethnicity variables into more meaningful measures. Biopsychosocial factors that may contribute to increased infant mortality in the African American population must be more closely examined, rather than maintaining the reductionist measure of race and ethnicity alone.

Programs aimed at reducing infant mortality must thus target appropriate demographic and risk factors in order to be effective. The factors identified in our models which are potentially modifiable include smoking during pregnancy and adolescent birth rate. Our data are consistent with other investigations associating adolescent pregnancy and smoking with infant mortality ${ }^{7}$.

Race and ethnicity may confound or modify the association between other risk factors and infant mortality. By determining ecological level risk factors for infant mortality we were able to adjust state infant mortality by calculating a standardized rate ratio. The standardized rate ratio has been advocated for risk adjustment for hospital quality improvement ${ }^{5}$. Much like hospital outcomes, state infant mortality is dependent on multiple factors including the intrinsic characteristics of the population. In our models of infant mortality the percentage non-Hispanic African American population of the state was associated with the majority of the variability in state infant mortality rates. Comparing states with a high proportion of non-Hispanic African American population 
such as Mississippi to those with a low non-Hispanic African American population such as Vermont may be misleading. Using a standarized rate ratio for infant mortality allows a comparison of infant mortality rates after adjusting for the demographics of the state population. In our analysis, many states with low infant mortality rates such as Vermont, New Hampshire and Maine have an infant mortality rate remaining low after risk adjustment. Other states with traditionally high rates such as Delaware and Louisiana remain high despite adjustment. However, states such as Mississippi, which has a traditionally high infant mortality rate fell within the standard 95\% confidence for infant mortality after adjustment. The adjusted infant mortality rates take into account factors in the multivariable models such as racial and ethnic demographics and smoking rates during pregnancy. States with adjusted infant mortality rates which are outliers must therefore explore factors above and beyond these adjusted risk factor effects to explain high or low adjusted infant mortality rates. Due to the exploratory nature and aggregate level of data in this research, we did not examine the interaction of race and ethnicity with the other risk factors and infant mortality in the model. Further research should endeavor to fully define the components of this complex measure.

Due to the ecologic design of our study, our finding that smoking during pregnancy and adolescent pregnancy are associated with state infant mortality are only generalizable at a state level rather than an individual level. We can not rule out the possibility that methodology of data collection differed between states. The aggregate data used in our study were obtained from secondary sources which were collected for differing reasons; therefore, misclassification of the variables in our study was not measurable as data were obtained at the aggregate level. Using summary data as risk 
factors may have lead to unstable or imprecise associations if large variability existed within the independent variables measured. There may have also been other important variables impacting infant mortality which we did not include in our analysis such as: maternal substance abuse, state hospital referral patterns, levels of neonatal intensive care and/or perinatal care and prevalence of birth defects or other hereditary conditions. Many of the independent variables used in our study, such as state demographic data, were obtained from 2000 Census Bureau data. Another limitation of our study is the possibility that major changes in state demographics occurred prior to the 2001 and 2002 period of our study. Our analysis used state health expenditure data from 1998, as this was the most comprehensive data we were able to obtain temporally related to our infant mortality analysis in 2001 and 2002. We can not rule out the possibility that expenditures for programs such as Medicaid or Supplemental Children's Health Insurance Program may have changed over time at the state level and subsequently impacted our findings. The multicollinearity of risk factors could not be measured in our study as data were obtained at the aggregate level. Race may be highly correlated with all of the modifiable risk factors in one or more states. It was not possible to control or remove these correlations from our analysis. Therefore, interpretation of these findings must be cautious.

In conclusion, the main findings of our study are that racial and ethnic demographics are associated with, and may confound, state infant mortality rates, and that infant mortality can be adjusted to control for the population demographics of a state. Additionally, our data indicate that teenage pregnancy and smoking were identified as two risk factors which may be potentially modifiable and therefore amenable to 
interventions aimed at reducing infant mortality. Further research should focus on those states that maintained a higher than expected IMR after controlling for demographics and risk factors. Our study identified ten states that fell above the standard range established with the U.S. adjusted rate ratio. These states must be closely examined using individuallevel data to determine the impact of these and other risk factors for infant mortality. As our analysis used an ecologic design, with aggregate data, our study was not undertaken to identify biological risk factors for infant mortality, but to explore modifiable or nonmodifiable risk factors. 


\section{References}

1. Centers for Disease Control and, Prevention. Racial/ethnic disparities in infant mortality--United States, 1995-2002. MMWR Morbidity \& Mortality Weekly Report. 2005;54:553-6.

2. Hoyert DL, Mathews TJ, Menacker F, Strobino DM, Guyer B. Annual summary of vital statistics: 2004. Pediatrics. 2006;117:168-83.

3. United States Census Bureau. Available at: http://factfinder.census.gov/home Accessed March 14, 2007.

4. National Center for Health Statistics. Available at: http://www.cdc.gov/nchs/ Accessed March 14, 2007.

5. Richardson D, Tarnow-Mordi WO, Lee SK. Risk adjustment for quality improvement. Pediatrics. 1999;103:255-65.

6. Salihu HM, Garces IC, Sharma PP, Kristensen S, Ananth CV, Kirby RS. Stillbirth and infant mortality among Hispanic singletons, twins, and triplets in the United States. Obstetrics \& Gynecology. 2005;106:789-796.

7. Centers for Disease Control and Prevention (CDC). Smoking during pregnancy-United States, 1990-2002. MMWR - Morbidity \& Mortality Weekly Report. 2004;53:911915. 
Table 1. Linear regression models of state infant mortality rates for 2001 and 2002 using National Center for Health Statistics data.

\begin{tabular}{|l|l|l|l|l|l|}
\hline \multicolumn{2}{|l|}{ Model 2001} & \multicolumn{2}{l}{ Model 2002 } \\
$\mathrm{r}^{2}=.69, \mathrm{p}<.01$ & $\beta$ & $\mathrm{r}^{2}=.81, \mathrm{p}<.01$ & Variables in Model & $\beta$ & $\mathrm{r}^{2}$ \\
\hline Variables in Model & & .56 & Percentage non-Hispanic & .64 & .65 \\
\hline $\begin{array}{l}\text { Percentage non-Hispanic } \\
\text { African-American Race }\end{array}$ & .52 & & African-American Race & & \\
\hline Smoking rate/pregnancy & .11 & .08 & Smoking rate/pregnancy & .22 & .09 \\
\hline Teen birth rate & .33 & .02 & Teen birth rate & .33 & .04 \\
\hline Percentage Hispanic & -.24 & .02 & Percentage Hispanic & -.24 & .03 \\
ethnicity & & & ethnicity & & \\
\hline BMI (\% women normal) & -.12 & .01 & Cesarean section rate & -.13 & .01 \\
\hline
\end{tabular}


Table 2. United States and State by State analysis of standardized rate ratio for both 2001 and 2002.

\begin{tabular}{|c|c|c|c|}
\hline & $\begin{array}{l}\text { Standardized } \\
\text { Rate Ratio } \\
\text { for } 2001\end{array}$ & $\begin{array}{l}\text { Standardized } \\
\text { Rate Ratio } \\
\text { for } 2002\end{array}$ & $\begin{array}{l}\text { Determination of } \\
\text { Range Placement } \\
\text { for } 2001 / 2002^{* \dagger}\end{array}$ \\
\hline $\begin{array}{l}\text { United States SRR } \\
(95 \% \mathrm{CI})\end{array}$ & $\begin{array}{l}.99 \\
(0.96-1.04)\end{array}$ & $\begin{array}{l}.99 \\
(0.97-1.03)\end{array}$ & \\
\hline Alabama & 1.02 & 1.03 & Expected/Expected \\
\hline Alaska & .98 & 1.18 & Expected/High \\
\hline Arizona & 1.10 & 1.03 & High/Expected \\
\hline Arkansas & .98 & .97 & Expected/Expected \\
\hline California & .96 & 1.0 & Expected/Expected \\
\hline Colorado & 1.0 & .96 & Expected/Expected \\
\hline Connecticut & 1.04 & 1.10 & Expected/High \\
\hline Delaware & 1.32 & 1.17 & High/High \\
\hline$D / C$ & .94 & .95 & Low/Low \\
\hline Florida & 1.06 & 1.08 & High/High \\
\hline Georgia & .96 & .96 & Expected/Low \\
\hline Hawaii & 1.10 & 1.19 & High/High \\
\hline Idaho & 1.03 & 1.09 & Expected/High \\
\hline Illinois & 1.05 & 1.06 & High/High \\
\hline Indiana & 1.0 & 1.02 & Expected/Expected \\
\hline Iowa & .85 & .90 & Low/Low \\
\hline
\end{tabular}




\begin{tabular}{|l|l|l|l|}
\hline Kansas & $\mathbf{1 . 0 9}$ & $\mathbf{1 . 0 5}$ & High/High \\
\hline Kentucky & .75 & .84 & Low/Low \\
\hline Louisiana & $\mathbf{1 . 0 6}$ & $\mathbf{1 . 0 5}$ & High/High \\
\hline Maine & .94 & .85 & Low/Low \\
\hline Maryland & 1.0 & .96 & Expected/Low \\
\hline Massachusetts & .88 & .86 & Low/Low \\
\hline Michigan & $\mathbf{1 . 0 5}$ & $\mathbf{1 . 0 8}$ & High/High \\
\hline Minnesota & .86 & .91 & Low/Low \\
\hline Mississippi & 1.0 & 1.01 & Expected/Expected \\
\hline Missouri & .97 & .98 & Expected/Expected \\
\hline Montana & $\mathbf{1 . 0 6}$ & $\mathbf{1 . 0 4}$ & High/High \\
\hline Nebraska & 1.03 & 1.08 & Expected/High \\
\hline Nevada & .88 & .91 & Low/Low \\
\hline New Hampshire & .67 & .86 & Low/Low \\
\hline New Jersey & 1.03 & 1.04 & Expected/High \\
\hline New Mexico & $\mathbf{1 . 1 4}$ & $\mathbf{1 . 0 7}$ & High/High \\
\hline New York & .88 & .98 & Low/Expected \\
\hline North Carolina & 1.0 & .97 & Expected/Expected \\
\hline North Dakota & $\mathbf{1 . 4 2}$ & $\mathbf{1 . 2 7}$ & High./High \\
\hline Ohio & $\mathbf{1 . 1 1}$ & $\mathbf{1 . 1 0}$ & High./High \\
\hline Oklahoma & .94 & 1.03 & Low/Expected \\
\hline Oregon & .88 & Low/Low \\
\hline Pennsylvania & 1.02 & & Expected/Expected \\
\hline
\end{tabular}




\begin{tabular}{|l|l|l|l|}
\hline Rhode Island & 1.07 & 1.04 & High/Expected \\
\hline South Carolina & .96 & .96 & Expected/Expected \\
\hline South Dakota & 1.11 & .95 & High/Low \\
\hline Tennessee & 1.03 & 1.06 & Expected/High \\
\hline Texas & .85 & .89 & Low/Low \\
\hline Utah & .83 & .89 & Low/Low \\
\hline Vermont & .93 & .83 & Low/Low \\
\hline Virginia & 1.02. & .98 & Expected/Expected \\
\hline Washington & .94 & .90 & Low/Low \\
\hline West Virginia & .95 & 1.05 & Low/High \\
\hline Wisconsin & 1.06 & 1.0 & High/Expected \\
\hline Wyoming & .94 & .98 & Low/Expected \\
\hline
\end{tabular}

"Expected = within United States 95\% CI; Low = below 95\% CI; High = above 95\% CI.

${ }^{\dagger}$ Italicized states fell below the 95\% CI in both 2001 and 2002.

${ }^{\sharp}$ Italicized-bolded states fell above the 95\% CI in both 2001 and 2002. 